SCHWEITZER, Franz Josef, Meister Eckhart und der Laie. Ein antihierarchischer Dialog des 14. Jahrhunderts aus den Niederlanden

\title{
Gilbert Fournier
}

\section{(2) OpenEdition}

\section{Journals}

Édition électronique

URL : http://journals.openedition.org/ifha/1378

DOI : $10.4000 /$ ifha. 1378

ISSN : 2198-8943

Éditeur

IFRA - Institut franco-allemand (sciences historiques et sociales)

Référence électronique

Gilbert Fournier, «SCHWEITZER, Franz Josef, Meister Eckhart und der Laie. Ein antihierarchischer Dialog des 14. Jahrhunderts aus den Niederlanden ", Revue de l'IFHA [En ligne], Date de recension, mis en ligne le 01 janvier 1999, consulté le 22 septembre 2020. URL : http://journals.openedition.org/ifha/1378 ; DOI : https://doi.org/10.4000/ifha.1378

Ce document a été généré automatiquement le 22 septembre 2020.

(C)IFHA 


\title{
SCHWEITZER, Franz Josef, Meister Eckhart und der Laie. Ein antihierarchischer Dialog des 14. Jahrhunderts aus den Niederlanden
}

\author{
Gilbert Fournier
}

À l'occasion d'un vibrant plaidoyer en faveur d'un »retour aux sources«, publié en 1995 au sein du volume collectif intitulé Passés recomposés. Champs et chantiers de l'histoire, Jean-Louis Gaulin déplore que "l'édition critique des textes et documents de l'histoire du Moyen Âge demeure depuis plusieurs décennies le parent pauvre d'une discipline par ailleurs très dynamique« et pose la question suivante: »Le travail de publication de sources est l'un des plus traditionnels en histoire médiévale. Faut-il pour autant abandonner les éditions critiques de textes comme semblent s'y résoudre les historiens français (...)?«, et ajoute tel un aparté: »à la différence de leurs collègues allemands«. L'ouvrage de F.J.S. accrédite doublement ce constat, en témoignant d'une part de la vitalité de la philologie allemande et d'autre part de l'attachement indéfectible de certains de ses représentants aux principes de l'édition critique.

Alors même qu'un seul exemplaire intégral du dialogue Maître Eckhart et le frère lai est conservé, F.J.S. renonce expressément à une édition diplomatique au profit d'une édition critique (p. CXV), en mobilisant les huit autres témoins de la tradition manuscrite, dont le texte fragmentaire se résume au mieux à quelques rares feuillets, entachés le cas échéant de remaniements textuels non négligeables. (Voir en particulier les manuscrits Wiesbaden, Hessisches Hauptstaatsarchiv 3004 B 10, f. 104-108: vraisemblabement originaire des Pays-Bas, 1410; La Haye, Bibliothèque Royale, KA XXXVII, f. 223rb-227vb: vraisemblablement originaire de la région de Delft, seconde moitié du XVe s.). Mais il y a plus: les caractéristiques propres au principal témoin de la tradition manuscrite du dialogue, le manuscrit Bruxelles, Bibliothèque Royale, Ms 888-890, f. 205va-285vb (B1), compromettent grandement le projet poursuivi par F.J.S. d'»une reconstruction aussi fidèle que possible du texte auctorial« (p. CXV). En effet, à 
une datation tardive, le manuscrit B1 est le fruit du labeur de deux scribes attestés au milieu du XVIe s. au couvent de Bethléem, situé à Herent, non loin de Louvain (p. LXXXI et suiv.), s'ajoute la qualité intrinsèque du texte consigné dans le manuscrit $\mathrm{B} 1$, dont l'auteur reconnaît qu'il accueille les leçons d'»au moins deux copistes antérieurs (XY, $\mathrm{X})$ « (p. CV), ce dont témoigne plus loin l'emplacement qui lui est assigné dans le stemma codicologique reproduit à la page CXIII. Dans ces conditions, l'édition critique du dialogue Maître Eckhart et le frère lai relève de la gageure.

Les quelques réserves émises précédemment n'amoindrissent en aucune façon les mérites de F.J.S.: en livrant la première édition intégrale d'un dialogue moyennéerlandais mettant au prise Maître Eckhart et un frère lai, ce dernier verse une contribution importante à deux débats qui animent aujourd'hui la communauté scientifique, soit respectivement l'émergence des laïcs sur la scène intellectuelle et spirituelle à la fin du Moyen Âge et la postérité de Maître Eckhart dans les contrées rhéno-flamandes.

La légitimation de la parole laïque en matière de théologie et de mystique constitue sans conteste l'un des enjeux majeurs du dialogue. Cette entreprise connaît une mise en scène spectaculaire aux questions 112 et 117 , où un »laïc « (leec) et un groupe de »femmes bien disposées" (goetwilleghe vrouwen) apportent la contradiction successivement à un prêtre et à un membre de l'ordre de saint Dominique. Acculé, le premier nommé brandit un missel et réitère sa dignité de "maître des Saintes Écritures« (p. 93, 52-55). L'émancipation du discours laïc équivaut donc à une remise en cause du magistère de l'Église, ce qui a valu au dialogue Maître Eckhart et le frère lai l'épithète d'»antihiérarchique« dès sa découverte par C.G.N. de Vooys en 1910, et en conséquence son ancrage dans les mouvements déviants du XIVe s. Tour à tour, l'auteur du dialogue endossa l'habit des béghards, des frères du Libre Esprit, des adeptes de Bloemardinne, etc. (voir la liste exhaustive p. LXII).

L'intérêt de l'enquête menée par F.J.S. est de rompre avec le raisonnement déductif qui a prévalu jusqu'alors dans la littérature secondaire, en établissant au plus près du texte le portrait des "goetwilleghe leken« qui concentrent toute l'attention de l'auteur du dialogue (p. XXV et suiv.). F.J.S. démontre qu'ils incarnent peu ou prou l'idéal des frères et sœurs convers, des tertiaires voire des béguines et des béghards (p. L-LI), placés dans le sillage du couvent des bénédictines de Rijnsburg près de Leyde (voir en particulier $p$. LIX et suiv.). Ces populations laïques constitueraient les destinataires du dialogue. Son auteur compterait au nombre des confesseurs des bénédictines, F.J.S. privilégiant un moine noir en raison de l'invocation de saint Benoît et de l'influence des Sermons de Limbourg (p. LXIII). C'est donc à tort que l'on recherchera une "spiritualité laïque« (Laienspiritualität, p. VIII) dans le dialogue Maître Eckhart et le frère lai, il s'agit davantage d'une tentative de transmettre les valeurs de la vie monastique à une population laïque (p. LXI) ou, selon l'heureuse expression de M. Eemans, »un véritable catéchisme mystique à l'usage des âmes simples« (Marcel EEMANS, »Maître Eckehart et la mystique néerlandaise«, in : Hermès, 4, juillet 1937, p. 84-90, ici p. 89).

Dans ces conditions, on ne s'étonnera pas de l'absence d'emprunts explicites aux œuvres de Maître Eckhart. Son enseignement théologique y est le plus souvent réduit à sa plus simple expression, c'est-à-dire à des considérations pratiques susceptibles d'accompagner le chrétien dans sa vie quotidienne (Voir par exemple le commentaire à la question 46 aux pages 201-202.) Pour l'essentiel, comme le remarque F.J.S. (p. VII), le dialogue Maître Eckhart et le frère lai s'autorise davantage de sa personne que de sa 
doctrine. Quant au procès qui assombrit les dernières années de la vie de Maître Eckhart, F.J.S. en récuse à bon escient toute incidence sur la rédaction du dialogue (p. LXXI-LXXII), d'où sa datation tardive, vers 1340-1341 (p. LIII), bien qu'ensuite l'auteur soit tenté de nuancer son propos et d'instiller quelques uns des enjeux ayant conduit aux événements colonais (l'opposition doctrinale entre franciscains et dominicains, les dissensions au sein de la communauté dominicaine de Teutonie) dans son commentaire (p. LXXIII-LXXVII). Ainsi était-il amené à réviser l'attribution du dialogue qui dorénavant serait l'œuvre d'un dominicain partisan d'Eckhart et des réformes (p. LXXVIII-LXXIX). À tort, comme il nous semble.

À l'introduction succède l'édition critique du dialogue (p. 17-183), puis un commentaire historique et doctrinal (p. 185-238).

Gilbert FOURNIER 